\title{
Bilateral Mixed Laryngocele
}

Rohan Gupta, Sachin Gupta, Arshad Bhat, Parmod Kalsotra, KP Singh, Om Prakash, Saurabh Gupta

\begin{abstract}
Laryngocele is a rare, benign dilatation of the laryngeal saccule that may extend internally into the airway or externally through the thyrohyoid membrane. The incidence of laryngocele is 1 per 2.5 million people per year. It may be asymptomatic or sometimes may present with cough, hoarseness, stridor, sore throat and as a swelling on one or both sides of the neck. We are reporting a case of bilateral mixed laryngocele in a 41 years old male, its clinical presentation and investigations along with a review of literature.
\end{abstract}

Keywords: Laryngocele, Saccule, Neck swelling, Computed, Tomography.

How to cite this article: Gupta R, Gupta S, Bhat A, Kalsotra P, Singh KP, Prakash O, Gupta S. Bilateral Mixed Laryngocele. Int J Phonosurg Laryngol 2013;3(2):69-72.

\section{Source of support: Nil}

Conflict of interest: None declared

\section{INTRODUCTION}

The laryngeal ventricle of Morgagni is normally a small elliptical recess located between the false cords above and true vocal cords below. The anterosuperior aspect of this recess ends in a blind pouch, which is called the appendix of the ventricle of Morgagni or saccule. A laryngocele is an abnormal saccular dilatation of the appendix of the laryngeal ventricle of Morgagni. It forms an air sac lined with pseudostratified ciliated columnar epithelium, which maintains its communication with the ventricle by means of a narrow stalk. ${ }^{1}$

Laryngocele is of three types namely internal, external and combined or mixed, according to its relationship with the thyrohyoid membrane. ${ }^{2}$ Internal laryngocele is one that is located medial to the thyrohyoid membrane and usually compresses the false vocal cords causing hoarseness or airway obstructive symptoms. External laryngocele extends through the thyrohyoid membrane, presenting as cervical mass and mixed (most common) laryngocele presents with both the internal and external components with their respective symptoms. An external laryngocele does not occur without an internal component. ${ }^{3}$

Usually, laryngocele is unilateral and combined. They may present at any age, but are most commonly seen in the 5 th -6 th decade. ${ }^{4}$ It is more frequent in men than in women with a ratio of 5 to $1 .{ }^{5}$ Although very rare, bilateral presentation of laryngocele has been reported. ${ }^{6,7}$

\section{CASE REPORT}

A 41-year-old male working in police department presented to ENT OPD with a 2 years history of hoarseness of voice and swelling left side of neck which had slowly increased in size. It was associated with forceful speaking and feeling of foreign body sensation with continuous throat clearing. There were no complaints of cough, sore throat, dyspnea, stridor, throat pain, necessity of persistently swallowing the secretions and difficult neck movements. History of smoking was present for the past 20 years (2-3 cigarettes/day). There was no past history of laryngeal problems, neck infections or laryngeal surgery.

The general physical examination of the patient was normal. Otolarygological examination revealed a painless rounded cystic swelling on left side of neck, in front of upper one third of the anterior border of sternocleidomastoid and below the angle of mandible, measuring about $4 \times 5 \mathrm{~cm}$ in size with normal overlying skin. It was manually reducible and increased in size on coughing and on valsalva. Conduction of vibrations during speech was also present. Indirect laryngoscopic examination revealed a bulge at the level of left false cord, rest of the larynx and vocal cords were normal.

Patient was adviced plain X-ray soft tissue neck anteroposterior and lateral views. The X-ray revealed large air filled lesions in bilateral paralaryngeal locations extending beyond the hyoid bone on both sides. No air fluid level was noticed within the lesions and no abnormal prevertebral shadow was seen (Fig. 1).

Ultrasonography of neck showed air filled cavities on both sides with reverberation artifacts (Fig. 2).

Noncontrast-enhanced computed tomography (NCCT) showed large well defined air filled lesions in both the paraglottic spaces that were seen extending beyond the hyoid bone on both the sides, dissecting the thyrohyoid membranes. The left one was larger than the one on right side and was seen to displace the left submandibular gland anteriorly and left sternocleidomastoid posteriorly. No internal fluid level was noticed inside the lesions on either side. No mucosal abnormality or thickening or irregularity was noted. No enlarged cervical lymph node was seen (Fig. 3).

Patient was adviced surgical excision of the symptomatic laryngocele which was on the left side but refused the same. Patient was then adviced follow-up after 1 month to reconsider his decision regarding surgery.

\section{DISCUSSION}

The first description of laryngocele was provided in 1829 by Dominique Larrey, who as a surgeon of the Napoleon army in Egypt noticed the occurrence of elastic bulging on the 

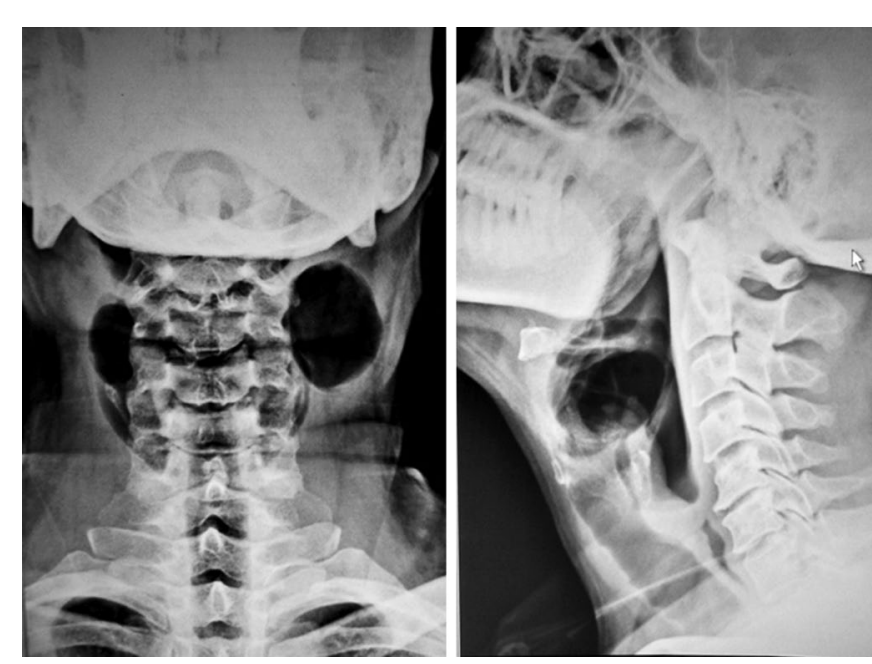

Fig. 1: X-ray soft tissue neck AP, lat showing bilateral air filled lesions in paralaryngeal location below level of hyoid bones

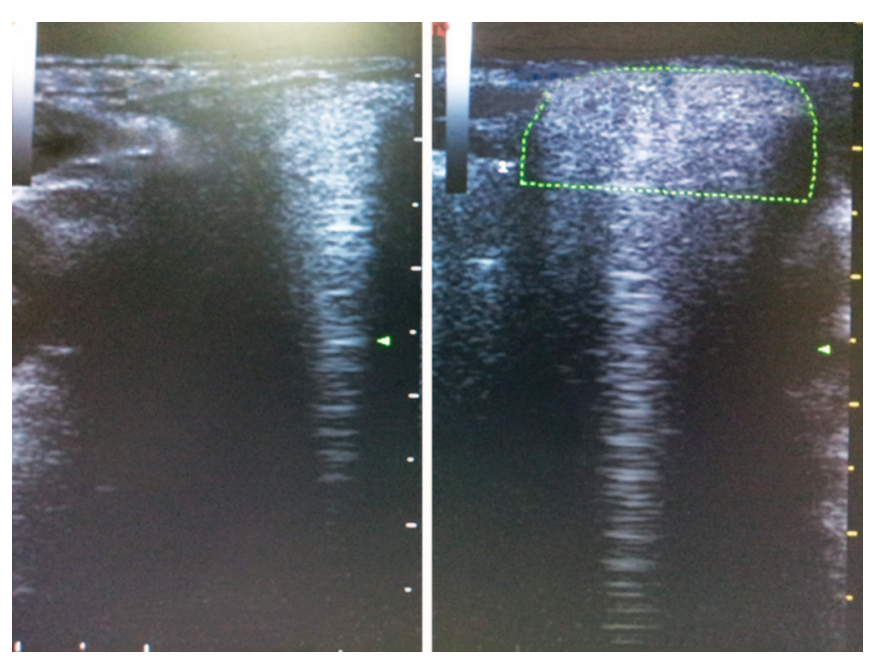

Fig. 2: Ultrasound images of bilateral paralaryngeal neck swellings showing dirty posterior acoustic artifacts that suggested air filled lesions on ultrasound
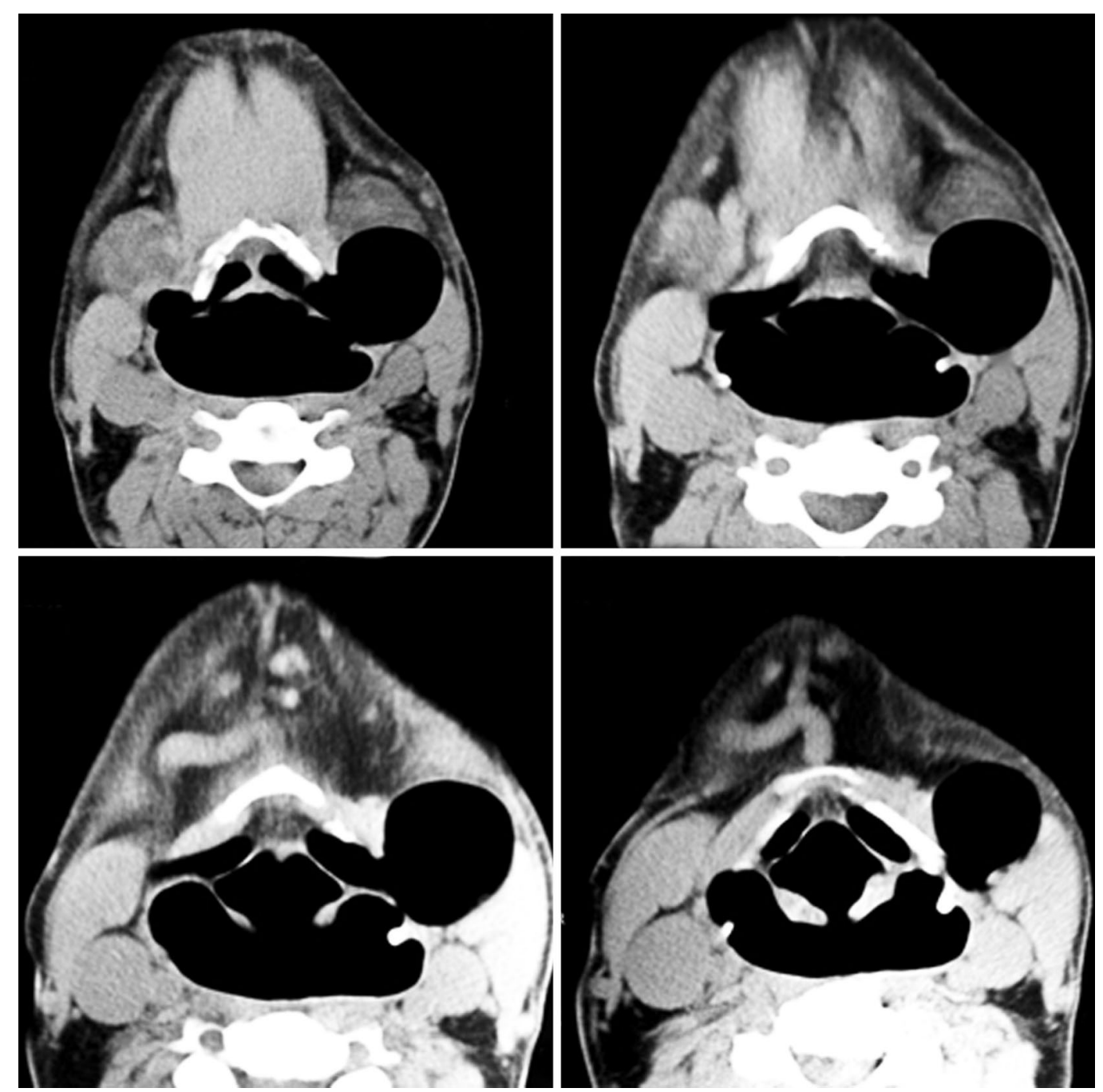

Fig. 3: NCCT axial images of neck below the level of hyoid showing bilateral mixed larynoceles; left larger than right. No fluid level or mucosal abnormality was noticed

necks of Egyptian street tub-thumpers, blind Koran singers and soldier's drill instructors. However, Virchow, in 1867, was the first to call this abnormal dilation of the laryngeal ventricle a laryngocele.
Laryngocele may be congenital or acquired and occur at any age. Laryngocele has been reported to be five to seven times more frequent in males, with a peak incidence in the sixth decade of life. ${ }^{1}$ The estimated incidence of laryngocele 
is 1 per 2.5 million people per year. Eighty-five percent of laryngoceles have been found to be unilateral without any right or left side predominance. ${ }^{2}$

The etiology is unknown and unclear, ${ }^{8}$ but there is an interrelation between a congenital predisposition - represented by a large ventricular appendix, ${ }^{9}$ e.g., a congenital laryngocele which causes respiratory distress in a newborn ${ }^{10}$ and other postnatal acquired factors, for instance, laryngeal papillomatosis in a child. ${ }^{9}$ An acquired laryngocele may develop when the laryngeal ventricle becomes functionally obstructed as a result of an increase in intraglottic pressure, such as that caused by excessive coughing, playing a wind instrument, glass blowing, ${ }^{8,11-13}$ after performing Valsalva manoeuvre ${ }^{14}$ or using ventricular phonation during speech. ${ }^{11}$

Laryngocele may extend internally into the airway or externally through the thyrohyoid membrane, ${ }^{11}$ so it may present as internal, external or mixed internal and external laryngocele. ${ }^{15-21}$ It may be unilateral (uncommon) $)^{8,11,15}$ or bilateral (rare). ${ }^{11,16,19}$

Laryngocele may be asymptomatic and incidentally discovered through radiographic studies for unrelated symptoms. ${ }^{6,8,11}$ The main symptoms, at presentation, are: airway obstruction, ${ }^{13,17,20}$ increasing stridor, ${ }^{12,18}$ hoarseness, ${ }^{12,18-21}$ sore throat, cough, pain, snoring, globus sensation $^{12}$ or a visible or palpable mass in the neck. ${ }^{5,14,19,20}$

Internal laryngocele presents with hoarseness of voice, dyspnea and sensation of foreign body. On indirect laryngoscopy a swelling/fullness of false vocal cords and aryepiglottic fold region with normal overlying mucosa is seen. External laryngocele presents as a mass evident in the lateral aspect of the neck, which is round or ovoid, soft, elastic, moveable, painless and covered with normal skin. It decreases in size by gentle palpation and pressure as the air escapes in the larynx. Mixed laryngocele produces the subjective symptoms of internal laryngocele and the objective signs of an external laryngocele. Almost pathognomonic of the mixed type of laryngocele is the rapid, sudden worsening of symptoms, especially dyspnea following compression of the external component. The passage of air from the external to the internal part of the sac results in sudden enlargement of internal component of laryngocele and it may cause acute upper airway obstruction. ${ }^{1,2,4,5}$

Serious forms of clinical emergency requiring tracheotomy may occur. ${ }^{13,20}$ There is a rare, but welldocumented, association of laryngocele with laryngeal carcinoma. ${ }^{6,15,19,21}$ Therefore, if a laryngocele is detected clinically or radiologically, a carcinoma must be taken into consideration and appropriate tests be performed. ${ }^{16}$

The diagnosis of laryngocele is essentially a clinical one. Plain X-ray soft tissue neck in anteriorposterior and lateral views are of value, especially if the Valsalva maneuver is performed. Ultrasonographic examination of neck is also useful. Computed tomography provides a cross-sectional image and superior contrast resolution and has replaced many conventional techniques and has become the initial radiographic method of evaluating the larynx and neck. It is the also useful investigation in cases with suspicion of concomitant laryngeal pathology. Uncomplicated laryngocele appear on CT as air filled structures lying in the para-laryngeal space (internal), lateral neck (external) or in both locations (mixed). Magnetic resonance imaging, because of its multiplanner capability provides high definition of soft tissues, offers detailed information on the boundaries of the air-filled sac and, is useful when laryngomucocele or laryngopyocele are suspected. MRI is also helpful to distinguish obstructed mucus and inflammation from neoplastic disease. $^{22-24}$

Differential diagnosis includes saccular cyst, branchial cyst, neck abscess and lymphadenopathy. Saccular cysts do not communicate with the laryngeal lumen, and it is usually filled with fluid. ${ }^{1,4}$

Treatment of laryngocele is surgical. External surgery is preferred for large or external laryngocele, while endoscopic resection is favored for small, internal laryngocele. External approach provides an excellent exposure during the dissection of the plane between the neck of laryngocele and surrounding paraglottic tissue. Further this approach offers less recurrence rate, minimal morbidity and negligible complications. ${ }^{21,25,26}$ Endoscopic resection with $\mathrm{CO}_{2}$ laser is the treatment of choice in patients with internal laryngocele. It requires lesser operation time and causes minimal damage to the endolarynx and vocal folds. The quality of voice and swallowing functions can be preserved. ${ }^{21,26}$

The mixed laryngocele can be completely removed via an external cervical approach, however a combined external and endoscopic laser approach to ensure complete removal of the mixed laryngocele has been advocated. ${ }^{14,25,26}$

\section{REFERENCES}

1. Holinger LD, Barnes DR, Smid LJ, Holinger PH. Laryngocele and saccular cysts. Ann Otol Laryngol 1978; 87(5 Pt 1):675-685.

2. Verret DJ, DeFatta RJ, Sinard R. Combined laryngocele. Ann Otol Rhinol Laryngol 2004;113:594-596.

3. Som PM. Cystic lesions of the neck. Postgrad Radiol 1987; 7:209-236

4. Amin M, Maran AG. The aetiology of laryngocoele. Clin Otolaryngol Allied Sci 1988;13(4):267-272.

5. Stell PM, Maran AG. Laryngocoele. J Laryngol Otol 1975; 89(9):915-924.

6. Akbas Y, Unal M, Pata YS. Asymptomatic bilateral mixed-type laryngocele and laryngeal carcinoma. Eur Arch Otorhinolaryngol 2004;261(6):307-309.

7. Isaacson G, Sataloff RT. Bilateral laryngoceles in a young trumpet player: case report. ENT Journal 2000;12(2):272-273. 
8. Erdogmus B, Yazici B, Ozturk O, Ataoglu S, Yazici S. Laryngocele in association with ankylosing spondylitis. Wien Klin Wochenschr 2005;117:718-720.

9. Altamar-Rios J, Morales Rozo O. Laryngocele and pyolaryngocele. An Otorinolaringol Ibero Am 1992;19:393-399.

10. Zelman WH, Burke LI. External laryngocele: an unusual cause of respiratory distress in a newborn. Ear Nose Throat J 1994; 73:19-22.

11. Dray TG, Waugh PF, Hillel AD. The association of laryngoceles with ventricular phonation. J Voice 2000;14:278-281.

12. Gallivan KH, Gallivan GJ. Bilateral mixed laryngoceles: simultaneous strobovideolaryngoscopy and external video examination. J Voice 2002;16:258-266.

13. Pennings RJ, Van den Hoogen FJ, Marres HA. Giant laryngoceles: a cause of upper airway obstruction. Eur Arch Otorhinolaryngol 2001;258:137-140.

14. Drozd M, Szuber K, Szuber D. The significance of the valve mechanism in pathology of laryngocele. Otolaryngol Pol 1996; 50:17-20.

15. Gierek T, Majzel K, Slaska-Kaspera A. Laryngocele. Otolaryngol Pol 1997;51:550-554.

16. Gil Tutor E. Laryngoceles. Clinical and therapeutic study. An Otorhinolaryngol Ibero Am 1991;18:451-464.

17. Ingrams D, Hein D, Marks N. Laryngocele: an anatomical variant. J Laryngol Otol 1999;113:675-677.

18. Larsen JL, Lind O. Laryngocele. Tidsskr Nor Laegeforen 1991 111:1488-1489.

19. Luzzago F, Nicolai P, Tomenzoli D, Maroldi R, Antonelli AR. Laryngocele: analysis of 18 cases and review of the literature. Acta Otorhinolaryngologica Italica 1990;10:399-412.

20. Martinez Devesa P, Ghufoor K, Lloyd S, Howard D. Endoscopic $\mathrm{CO}_{2}$ laser management of laryngocele. Laryngoscope 2002; 112:1426-1430.

21. Matino Soler E, Martinez Vecina V, Leon Vintro X, Quer Agusti M, Burgues Vila J, de Juan M. Laryngocele: clinical and therapeutic study of 60 cases. Acta Otorhinolaryngol Esp 1995; 46:279-286.

22. Parsons CA, Chapman P, Courter RT, Grundz A. The role of computed tomography in tumors of the larynx. Clin Radiol 1980;31:529-533.

23. Kumar G, Bradley PJ, Wastie ML. What a blow! Br J Radiol 1998;71:799-800.

24. Mitroi M, Capitanescu A, Popescu FC, Popescu C, Mogoanta CA, Mitroi G, Surlin C. Laryngocele associated with laryngeal carcinoma. Rom J Morphol Embryol 2011;52:183-184.
25. Thome R, Thome DC, De La Cortina RAC. Lateral thyrotomy approach on the paraglottic space for laryngocele resection. Laryngoscope 2000;110:447-450.

26. Dursun G, Ozgursoy OB, Beton S, Batikhan H. Current diagnosis and treatment of laryngocele in adults. Otolaryngol Head Neck Surg 2007;136:211-215.

\section{ABOUT THE AUTHORS}

\section{Rohan Gupta (Corresponding Author)}

Postgraduate Student, Department of ENT and Head and Neck Surgery, Government Medical College, Jammu, Jammu and Kashmir, India Phone: +91-9419136333, e-mail: rohangupta5949@gmail.com

\section{Sachin Gupta}

Registrar, Department of ENT and Head and Neck Surgery, ASCOMS and Hospital, Jammu and Kashmir, India

\section{Arshad Bhat}

Registrar, Department of Radiodiagnosis and Imaging, Government Medical College, Jammu, Jammu and Kashmir, India

\section{Parmod Kalsotra}

Professor, Department of ENT and Head and Neck Surgery Government Medical College, Jammu, Jammu and Kashmir, India

\section{KP Singh}

Associate Professor, Department of ENT and Head and Neck Surgery Government Medical College, Jammu, Jammu and Kashmir, India

\section{Om Prakash}

Lecturer, Department of ENT and Head and Neck Surgery, Government Medical College, Jammu, Jammu and Kashmir, India

\section{Saurabh Gupta}

Postgraduate Student, Department of Radiodiagnosis and Imaging Government Medical College, Jammu, Jammu and Kashmir, India 